\title{
El derecho como aparato ideológico y represor del Estado
}

\author{
Yuner Ismar Flórez Eusse ${ }^{1}$ \\ Corporación Universitaria Americana
}

Recibido: 14/10/2019 - Aprobado 13/12/2019

DOI: https://doi.org/10.22490/26655489.3187

\section{Resumen}

Se pretende en el presente ejercicio de investigación postular la tesis sobre el derecho como dominación de las masas sociales, tanto ideológica como represora, de modo que vaya tomando forma dentro del paradigma de investigación socio jurídica para producir nuevos conocimientos en el campo del derecho y de la filosofía del derecho y que de este modo surjan nuevas alternativas teóricas y de aplicación en el campo socio jurídico en pro de los derechos humanos, la inclusión y la dignidad humana.

Palabras clave: derecho, dominación, ideología, principios, represión

\section{Introducción}

Los aparatos ideológicos y represores del Estado coaccionan las masas para que estas se mantengan enajenadas de sí mismas y no piensen autónomamente, sino que solo reproduzcan la ideología dominante, la cual se impone desde diferentes ángulos y convierte los individuos en autómatas con delirios de libertad. Esta libertad en su expresión más amplia solo existe para consumir bienes y servicios $y$, por supuesto, nada tiene que ver con las necesidades reales, sino que crea "seudo-necesidades"; es decir que el individuo contemporáneo es dependiente de unas lógicas mercantilistas donde todo tiene precio, incluso la misma dignidad humana. Es por ello que se pretende investigar este fenómeno en el derecho, donde se postula que este funciona como un aparato más del estado para mantener la clase menos favorecida cada vez más enajenada

1 Filósofo, Universidad Nacional Abierta y a Distancia; Abogado (en curso), Corporación Universitaria Americana, Colombia. yuner.florez@unad.edu.co 
de sí misma, con una vana ilusión de justicia, la cual solo aplica para que quien tradicionalmente detenta el poder del dinero y de la casta politiquera no solo nacional sino internacional.

\section{Objetivo general}

Reflexionar en torno a la dominación del derecho como aparato ideológico del Estado a través de la disertación filosófica y develar el poder del monopolio que tiene el derecho sobre la masa social.

\section{El derecho como aparato ideológico y represor del Estado}

Para dar inicio con la disertación en torno al derecho, es menester realizar una clarificación conceptual para efectos de lo que el presente trabajo requiere; lo primero sería puntualizar la diferencia entre el derecho como principio ontológico necesario y el derecho como instrumento del Estado para organizar, controlar y ordenar la sociedad. En cuanto al primero, se dilucida que la naturaleza del individuo es vivir en sociedad y que ella debe ser un vehículo para hacer de ese individuo cada vez más digno de seguir siendo. Desde esta perspectiva el derecho está directamente ligado con los principios primeros que constituyen la existencia misma del ser antropológico en relación con su entorno: es un derecho justo y equitativo porque le es dado a todos por igual pues conforma una licencia para obrar de tal o cual modo acorde con la voluntad individual; no obstante, la segunda forma de derecho tiene que ver con la regulación de las libertades individuales, donde se renuncia a una parte de ese derecho ontológico intrínseco al ser social, en pro de la convivencia y el orden, de modo que no se genere un caos en el ejercicio del derecho individual; sin embargo, tanto el derecho ontológico como el social han sido manipulados de tal modo que se han convertido en un instrumento fuerte para mantener ciertos intereses individuales de las clases más favorecidas económica y políticamente hablando.

Con un horizonte como el anterior, donde sale a flote la dominación de la masa social por parte de la clase elitista, donde un medio protagónico por excelencia ha sido el derecho tomado de manera general, es de vital importancia mirar cómo se ha ido 
conformando este poderoso aparato ideológico y represor del Estado. De este modo se designa "con el nombre de aparatos ideológicos de Estado cierto número de realidades que se presentan al observador inmediato bajo la forma de instituciones distintas y especializadas" (Althusser, L. 2003, p. 12). Es decir que se va conformando una serie de estrategias que se legitiman por medio de la aceptación de la masa misma y va introyectando una ideología determinada que a simple vista parece benévola y en pro de los intereses colectivo. Empero, en última instancia es un fiasco y por ello cada vez crece más la brecha entre la práctica y la teoría, pues desde la construcción misma ya está viciada de manera silenciosa y sutil en detrimento de los menos favorecidos y favoreciendo de algún modo a los que se perpetúan en el poder. Dichos aparatos ideológicos utilizan herramientas diferentes para que sea efectivo; es ahí donde sale a flote el aparato represor, pues si la ideología misma no hace mella sobre el individuo, sale la represión haciendo gala de la fuerza que ya está además legitimada y reprime a quien se está saliendo del cauce que ha sido trazado por los dueños del derecho que son los que detentan el poder adquisitivo legitimado.

\section{El derecho como dominación en la antigüedad}

Teniendo en cuenta lo anterior, se postula el derecho como el aparato ideológico dominante por excelencia en el Estado; en cuanto los demás aparatos, están al servicio de este, tanto los represores como los mismos ideológicos. Este fenómeno se ha ido perfeccionando a través de la historia de la humanidad pues desde la Antigüedad se trazó un norte para caminar por él. Valga decir que este sendero por donde han ido pasando las diferentes sociedades ha sido pensado y dirigido por la élite y si bien es cierto que no ha sido homogéneo ni rectilíneo como la historia elitista eurocéntrica lo ha querido hacer ver, sí sigue siendo dominante e influyente en el trazo de la historia. Se vislumbra entonces como en la Antigüedad en Grecia, que se considera como la cuna del pensamiento occidental, y por esa misma razón la madre de la exclusión y donde empezó a legitimarse la élite como dueña del derecho. Esto se deja ver en Aristóteles, uno de los filósofos más influyentes en la conformación del andamiaje social y político de todos los tiempos, quien postula que "así como el hombre perfecto es el mejor de los animales, así también, apartado de la ley y de la justicia, es el peor de todos" (Política, 1, 1253a, 
15). Es clara la ideología sobre la herramienta del derecho, que es la ley, donde si observa y obedece la ley es el mejor de los animales, pero si la deja de cumplir se convierte en el peor de ellos; en este sentido se está "terribilizando" al que se aparta del mandato legal para poder volcar el aparato represor sobre él sin que la masa desapruebe el acto sino que por el contrario lo apoye por la idea de justica que está emparentada con la ley, que por ende ha sido construida por la misma clase dominante. Si bien en Grecia nació la democracia, donde se supone el poder del pueblo, donde el ciudadano es libre y tiene participación e incidencia sobre el Estado, también lo es que el concepto de ciudadano era restringido para los hombres libres, que eran los que tenían las necesidades básicas cubiertas, el que no tenía que trabajar para poder comer y suplir sus necesidades y las de su familia; es decir, el que tuviera el poder económico y perteneciera a una casta determinada porque de nada vale tener el dinero pero no estar legitimado para poseerlo en un determinado lugar, situación que ocurría con los barbaros "por eso dicen los poetas: justo es que los helenos manden sobre los bárbaros, entendiendo que bárbaro y esclavo son lo mismo por naturaleza" (Política, 1, 1252b, 4).

Se dilucida entonces un elemento de exclusión y de marginalidad a quien no tenía un determinado linaje o capacidad. Así, además de virtuoso en el sentido de observar la ley el ciudadano debería de cumplir con una legitimación social basada en una especie de derecho natural en el sentido de contar con unas condiciones extrínsecas al dominio del individuo y es ahí donde se vislumbra también la manipulación de ese derecho ontológico que no escapa a la sed de poder del Estado; y se dice del Estado porque se dilucida que este tiene dueños y está manipulado por una clase legitimada; al ser así, el Estado no somos todos como lo han querido imponer, aunque somos parte de él en cuanto pertenecemos a él. No somos él. Es diferente ser algo a pertenecer a ese algo; es así como vuelcan la masa en contra de ella misma tergiversando la realidad y los principios constitutivos de ese ser antropológico pues al vender la idea de que todos somos este Estado, todo aquel que atente contra él está actuando en contra de todos y debe haber una justicia social igualmente manipulada ya que al estar tergiversado el principio mismo, razón de su existencia, el valor justicia no va a estar bien; se infunde una sed de venganza en el pueblo en nombre de la justicia que se justifica bajo el imperativo de que el bien social está por encima del bien 
individual, que desde los tiempos de Aristóteles se enunciaba de le siguiente manera: "procurar el bien de una persona es algo deseable, pero es más hermoso y divino conseguirlo para un pueblo y ciudades" (Aristóteles, 1094b, 5-10). El principio enunciado en cuanto tal no está mal por sí solo; lo que se aleja de la línea de lo conveniente para el ser antropológico es la manipulación del mismo en el sentido dicho con antelación y es lo que constituye quizá el problema fundamental: el piso sobre el que se erigen los principio sociopolíticos y legales está viciado y por ende lo que se erija sobre este no se ajusta a la realidad ontológica de las necesidades antropológicas sino que está pensado con una favorabilidad determinada. En consecuencia, la masa resulta manipulada defendiendo los intereses del monopolio y del poder.

\section{El derecho como dominación en la edad media}

Avanzando un poco en la historia, es notable la manipulación de los principios primeros que constituyen la acción legal y, como ya se ha visto, las ideas del conocimiento, la política y, por ende, el derecho. Este nació propiamente de la clase libre, es decir de los que detentaban el poder económico y político; este conocimiento filosófico se convirtió en autoridad, tanto que para que algo fuera válido, legitimado y creído por todos, bastaba que un filósofo lo hubiera dicho. Así, el poder dominante e ideológico nació en las escuelas filosóficas y se compaginaba con las normas de convivencia y con el castigo que debía de merecer quien no se ajustara a la ley. Los políticos y legisladores de la época echaron mano de la ideología para legitimar su poder, pues

"De todas las grandes cosas que se proclaman en las escuelas. Nada han dicho los filósofos, que sea recto y honesto, que no hayan descubierto y practicado los legisladores de los pueblos (...) De aquellos que habiendo depositado en la educación los gérmenes de estas virtudes, inculcaron unas en las costumbres y sancionaron las otras con las leyes". (Cicerón, p. 9)

Las virtudes depositadas en las escuelas son los gérmenes de la dominación. Por tanto, se postula que la educación es la doma del animal político para que interiorice la ley que lo rige y la obedezca de manera aparentemente volitiva. Se crea 
con la educación una sensación ilusoria y una concepción de libertad cuando en realidad se está convirtiendo al sujeto en el ente sujetado por el mismo Estado y cada individuo educado conforma un eslabón que ata a los demás miembros de la comunidad social y política. Esto se ve claramente reflejado en lo que referencia Cicerón:

"Dícese que habiendo preguntado al esclarecido filosofo Xenócrates que ganaban sus discípulos contesto: "aprenden a hacer por su propio impulso lo que las leyes mandan practicar" luego aquel ciudadano que consigue de todo un pueblo, por medio del saludable imperio y el freno de las leyes, lo que con su trabajo alcanzan los filósofos con sus discursos inculcar a unos pocos debe colocarse muy por encima de todos los doctores que acerca de tales cosas discurren". (p. 9)

Se dilucida cómo se pone a la par el trabajo del Estado en cuanto hacer cumplir la ley y el del filósofo, maestro de las sociedades que infunde sus enseñanzas de valores coaccionadores de las voluntades; sin embargo, se pone por encima que el ciudadano mismo aprenda mediante las vivencias políticas y sociales a vivir conforme a la ley que yendo a una escuela. Es ahí donde se hace necesaria la creación de un principio que coaccione no solo al que se educa, porque no todos tienen la posibilidad o la voluntad de hacerlo, sino que incida en todo ciudadano por escasos recursos que posea. En consecuencia, se fomenta un principio primero constitutivo de todo, en el sentido completo; este principio no está centrado en lo humano sino que se asienta sobre un ser abstracto extraterreno al que se le da todo el poder porque se convierte en principio y en fin de todo lo existente $y$ además es perfecto como ningún hombre o ser terrenal lo puede ser "El Ser Primero (mawuŷūd al-Iūal) es la causa primera (sabab al-Iūal) a la que deben su entidad todos los demás seres. Él está libre de toda especie de imperfección" (Abu Nasr Al-Farabi, p. 5). Esto implica una estocada a la humanidad y un avance sin precedentes en cuanto a la dominación del ser sujetado pues legitima un poder sin límites. Esto debido a que como el nuevo principio que sustenta las acciones de los gobernadores es perfecto y no cabe error, da a significar que las acciones que provengan de él están acordes con la voluntad divina lo que implica una resignación y sumisión a la ley, así esta no se ajuste a los intereses sociales. Ir en contra del poder que domina sería 
equivalente a ir contra del principio rector y esto implicaría una caída inminente pues "El Uno Verdadero es por tanto el Primero, el Creador (al-mubdi') que mantiene todas las cosas que él ha creado, y cualquier cosa [que] es libre de Su sostén y poder vuelve y perece" (Al Kindi, 1974, p. 90). Es de resaltar entonces, el hecho de que todo lo existente e incluso las mismas dinámicas socioeconómicas se ligaran de manera directa con el principio rector que en este caso es el ser abstracto, el cual, a pesar de ser autónomo necesitaba del hombre, pues:

"El Principio de todo es una esencia necesaria, pero el Ser Necesario necesita de todo lo que existe a partir de Él, pues de otro modo tendría una disposición que no existiría, y de este modo no sería necesario en todos sus aspectos". (Avicena, 1950, p. 450)

Se vislumbra entonces el hecho de sujeción del ser antropológico a un principio rector que además necesita del hombre mismo para que la existencia de dicho ser sea perfecta. En este sentido se está adhiriendo ideológicamente el individuo a un elemento poderoso que además necesita del él, lo que conlleva a un servilismo, no hacia el humano mismo sino hacia un ser abstracto que no tiene nada que ver con el mundo inmediato; es decir, la amenaza de pagar el mal comportamiento se traslada a un campo de eternidad después de la vida. En consecuencia, no tiene ningún sentido la rebeldía o la desobediencia en la tierra pues el principio se encargará de todo; es en ese más allá donde se dará la justicia ya que según Santo Tomás "el bien que es fin de todo el universo, por necesidad ha de estar fuera del mismo universo" (De Aquino III, C. 1003. a 2). Con base en este concepto nace la idea de que el hombre está predispuesto al pecado y a la maldad por naturaleza por una culpa que ya trae consigo de manera original.

"La justicia original, en la que fue creado el primer hombre, era un accidente de la naturaleza de la especie, no causado por los principios de la especie, sino por un don infundido por Dios a toda la naturaleza, esto es evidente, porque las cosas opuestas están en un mismo género, y se dice que el pecado original, como opuesto a la justicia original, es un pecado de naturaleza. Por eso pasa de padres a hijos. Por lo mismo, también se transmitirá la justicia original". (De Aquino, III, c 100, a. 1) 
Desde esta perspectiva se vislumbra un predeterminismo tanto del bien como del mal, lo que implica que la acción humana está supeditada a la voluntad superior, pues "la perfección última de cada cosa se encuentra en la consecución del fin. Por eso, a la bondad divina pertenece el que, así como produce el ser de las cosas, así también las lleve a sus fines, esto es gobernarlas" (De Aquino, III, C. 1003. a 1). Al ser el mundo gobernado por una fuerza y voluntad superior, el gobernante como tal se exime de las responsabilidades terrenas porque incluso él (según esta ideología) está sometido a los designios de Dios. Además de legitimar el despotismo en el sentido de apoyar una voluntad unívoca excluyente, se legitima al mismo tiempo el mal gobierno pues si algo está saliendo mal no depende de lo humano mismo sino de lo extraterreno. Como reitera Santo Tomás, uno de los doctores de la iglesia, herederos de Aristóteles, más influyentes de la época: "Hay que decir, por lo mismo que Dios es creador de las cosas, también es gobernador de ellas. Porque a uno mismo pertenece dar origen a las cosas y llevarlas a su perfección que es función propia del gobernante" (III, C. 1003. a 3).

Esto en materia de derecho ha dejado consecuencias aún hoy latentes que van en detrimento del ser humano en cuanto no está acorde con lo que es la naturaleza misma del derecho y del ser mismo, pero no naturaleza, como se concibió en la época medieval, sino conforme a los principios antropológicos que se deducen de lo que le es propio al hombre y de la potencia como capacidad de llegar a ser que reside en este. Es una posibilidad evidente la manipulación de la concepción del aparato jurídico y de los fines mismos del ser, de la política y del derecho que se implantaron desde los inicios mismos de los tiempos a través de la ideología dominante utilizando medios como las escuelas mismas, la iglesia y el discurso político, que es una retórica que solo busca un triunfo por medio del convencimiento manipulando la realidad en pro de unos intereses particulares. Estos elementos se fueron convirtiendo en autoridades irrefutables; se prohibía hablar o disidir de lo establecido políticamente, que por supuesto era tácita en el derecho, lo que vicia la praxis legal desde tiempos inmemoriales. Aún hoy tenemos gran influencia del derecho medieval en las sociedades contemporáneas donde lo primordial no es la dignidad y el respeto de lo humano sino un culto a lo abstracto, a un ser creado para dominar y distorsionar los principios antropológicos naturales que nada tiene que ver con lo que se conoce hoy como naturaleza humana. Lo anterior se 
vislumbra en la idea del juzgamiento de las malas acciones solo en un plano después de la vida; esto lo corrobora Agustín de Hipona cuando dice que:

Aunque es cierto que algunos, meditando atentamente sobre este punto, se arrepentirán y enmendarán de su pecado, otros, como dice el Apóstol, "no haciendo caso del inmenso tesoro de la divina bondad y paciencia con que los espera, se acumulan, con la dureza y obstinación incorregible de su corazón, el tesoro de la divina ira, la cual se les manifestará en aquel tremendo día, cuando vendrá airado a juzgar el justo Juez, el cual compensará a cada uno, según las obras que hubiere hecho". (De Hipona p. 25)

El derecho en este caso no tendría sentido si lo que se espera es una justicia y una regulación y recompensa de los actos, pero solo el día de la furia del justo juez, como llama Agustín al principio dominador. Se desvirtúa de este modo la esencia del derecho que está creado para la sociedad del aquí y proyectada al futuro, pero futuro sociopolítico no extraterreno. Esto sirve para reiterar de nuevo el vicio de que el derecho más que obrar en pro del orden humano está concebido para salvaguardar un ideal después de la vida; si se tiene en cuenta que mencionado ideal, como se ha podido ver, está planteado por la clase de mayor poder adquisitivo y que ha detentado el poder, por ende resulta el derecho favoreciendo entonces los interés de la clase dominante.

\section{El derecho como dominación en la modernidad}

El problema enunciado con antelación no ha sido un secreto. Sin embargo, es difícil hacer caer en cuenta de ello a la masa sumergida en el espectáculo inmediatista que ofrecen los que detentan el poder para mantener el equilibrio que permite la continuidad del sistema monopolizador y enajenador; varios pensadores han postulado el tema o al menos lo dejan entrever en sus obras, pero han sido mal interpretados por sus predecesores pues el mismo sistema de educación se convierte en un brazo del monstruo ideológico porque se educa para aprender lo que se debe obrar, mas no para la autonomía al pensar. "Sin pretenderlo, nuestras universidades son auténticos invernaderos en los que se produce una especie de atrofia de los 
instintos del espíritu" (Nietzsche, 2005, p.31). Es por ello que se legitima la dominación normalizándola para que no sea percibida y mucho menos denunciada por la masa; ya Nicolás Maquiavelo se había percatado de la brecha existente entre la esencia del derecho y la praxis del mismo y además enuncio con claridad en su libro, quizá el más célebre, El Príncipe, que si el aparato dominante quería mantener el poder, tendría que obrar del tal modo que no se ajustara al deber ser del derecho sino al ser, que es la dominación misma para no perder el poder y la legitimación de ejercerlo. Mencionaba el autor que:

"Un príncipe, y especialmente uno nuevo, que quiere mantenerse, debe comprender bien que no le es posible observar en todo lo que hace mirar como virtuosos a los hombres; supuesto que a menudo, para conservar el orden en un Estado, está en la precisión de obrar contra su fe, contra las virtudes de humanidad, caridad, y aun contra su religión. Su espíritu debe estar dispuesto a volverse según que los vientos y variaciones de la fortuna lo exijan de él; $y$, como lo he dicho más arriba, a no apartarse del bien mientras lo puede, sino a saber entrar en el mal, cuando hay necesidad". (1998, p. 39).

Se dilucida además la sutileza que debe tener el aparato dominante en el sentido de saber entrar en el mal cuando sea necesario (está implícito el principio de prudencia silenciosa y cautelosa de modo que se haga ver un bien cuando en realidad se está en pro de mantener el poder dominante) al que le es lícito traspasar las barreras del bien y del mal que el mismo aparato ha establecido pero que el vulgo no se percata porque se utilizan principios justificadores que hacen ver la acción ideológica o represora como un sacrificio que se hace, como una licencia que tiene el gran organizador y regulador de los individuos y las sociedades, que es el que administra el derecho: la élite. Es lo que se viene afirmando de manera explícita cuando Maquiavelo postula que "el príncipe que se hace temer debe obrar de modo que, si no se hace amar al mismo tiempo, evite el ser aborrecido" (1998, p. 37). Esto se logra con la utilización de las leyes, que son el brazo directo del derecho, porque "es menester, pues, que sepáis que hay dos modos de defenderse: el uno con las leyes y el otro con la fuerza. El primero es el que conviene a los hombres; el segundo pertenece esencialmente a los animales. (Maquiavelo, 1998, p. 38). Se puede ver cómo 
la historia ha transcurrido y la dominación ha perdurado; se mantiene la idea de la imposición de la ley como arma de doble filo porque, como se ha enunciado antes, por un lado cumple con la función ideológico política en el sentido que enuncia el tipo de comportamiento que debe adquirir un ciudadano determinado dependiendo de la coyuntura social y política por la que se esté pasando en determinado lugar $y$, por otro, quien no se ajuste con la sola pedagogía y discurso se presiona legítimamente. Ya en plena modernidad enuncia uno de los teóricos e influyentes de la política moderna y contemporánea que:

"Los pactos que no descansan en la espada no son más que palabras, sin fuerza para proteger al hombre, en modo alguno. Por consiguiente, a pesar de las leyes de naturaleza (que cada uno observa cuando tiene la voluntad de observarlas, cuando puede hacerlo de modo seguro) si no se ha instituido un poder o no es suficientemente grande para nuestra seguridad, cada uno fiará tan solo, y podrá hacerlo legalmente, sobre su propia fuerza y maña, para protegerse contra los demás hombres". (Hobbes, p.70)

La cita anterior deja ver el principio de que el hombre por naturaleza sigue siendo malo, lo que legitima un poder de dominación ya no bajo el imperio de un dios, como se evidenció en la Edad Media, sino de un Estado mismo; es decir que el Estado cobró autonomía por sí mismo y ya no es necesario el principio justificador de una ley. Esto además muestra que cuando las sociedades evolucionan y ya no se ajustan a los aparatos de dominación, estos salen a la par con nuevas estrategias dominadoras que encajen en el tiempo coyuntural vigente; por ello al existir una transición donde el centro de la reflexión regresa al ser antropológico y al mundo próximo, sale la élite y se postula entonces que "ESTADO, en latín, CIVITAS. Esta es la generación de aquel gran LEVIATÁN, o más bien (hablando con más reverencia), de aquel dios mortal, al cual debemos, bajo el Dios inmortal, nuestra paz y nuestra defensa" (Hobbes, p.72). Se legitima entonces, el Estado mismo como ser autónomo producto de la maldad del hombre para protegerlo de sí mismo, lo que implica un supuesto pacto entre los seres sociales para renunciar a unos derechos en pro de los demás; esto se evidencia con la creación del Estado donde según Hobbes obedece a un fin: "el fin del Estado es, particularmente, la seguridad. Cap. XIII. La causa final, fin o designio de los 
hombres (que naturalmente aman la libertad y el dominio sobre los demás)" (Hobbes, p.70). Se deduce entonces una cualidad antropológica del hombre que es la de dominar sobre los demás para legitimar el poder del Estado; este poder está materializado y representado por un gobernante que regularmente ha hecho parte de la clase favorecida y tiene pactado con los dueños del poder adquisitivo el desarrollo sociopolítico en la medida que siga favoreciendo a los mismos que lo planean y que deciden lo que es conveniente o no para la masa que tiene una creencia infundada de participación y decisión pero en realidad decide sobre lo que ya está decidido y manipulado pues:

"El soberano es juez de lo que es necesario para la paz y la defensa de sus súbditos. Y juez respecto de qué doctrinas son adecuadas para su enseñanza. En sexto lugar, es inherente a la soberanía el ser juez acerca de qué opiniones y doctrinas son adversas y cuáles conducen a la paz; y por consiguiente, en qué ocasiones, hasta qué punto y respecto de qué puede confiarse en los hombres, cuando hablan a las multitudes, y quién debe examinar las doctrinas de todos los libros antes de ser publicados". (Hobbes, p.74)

La cita anterior trae como consecuencia lo que se ha postulado con antelación, donde la educación y la asistencia a las escuelas no garantizan un saber o un conocimiento fidedigno, sino que se sabe sobre lo que otros han decidido lo que se debe saber; por ello en la actualidad se da mayor crédito e importancia a los saberes técnicos ya que estos no implican reflexión sino acción. Esto se perfeccionó en la modernidad con el método científico y el paradigma tecno-cientificista, que ha proporcionado el avance de la industria y de la producción económica puesta por encima del desarrollo humano; por el contrario, el individuo cada vez se reprime con mayor vehemencia y se endosa con las lógicas de dominación legitimadas por el derecho que favorece lo que produce dinero y poder, incluso en detrimento del objeto de su misma ciencia. Es así como se considera que "el hombre ha nacido libre, y sin embargo, vive en todas partes entre cadenas" (Rousseau, 1999, p.4).

Cadenas a las que el mismo hombre se aferra con todas sus fuerzas bajo la premisa de que esa misma cadena será la que le dará libertad y que pedirá por él lo que requiere como hombre de un Estado, pero es solo una utopía viciada desde 
su principio porque la cadena que aprieta y que afloja es el derecho, que es operativo con las leyes, que no están a favor de la persona del común sino de los intereses del Estado y más que del Estado de unos pocos que dirigen el Estado pues "es manifiesto que la medida de las buenas y de las malas acciones es la ley civil, y el juez es el legislador que siempre representa al Estado" (Hobbes, p. 132).

En este sentido los funcionarios del aparato jurídico funcionan como los vigías del patrimonio de quien lo detente en mayor cantidad; estos son los brazos extensivos del Estado que, sin ser parte de los poderes, vigilan y sirven como ejes de la trama de la construcción y mantenimiento de la masa en la ignominia psicológica y económica por medios legitimados por la misma turba, a quien solo interesa el espectáculo inmediatista y las discusiones vacías que supuestamente van a mejorar sus condiciones egoístas. "Los individuos y los grupos buscan el poder para promover sus propios intereses, incluyendo, en particular, su propio interés pecuniario" (Galbraith y Aleu, 1984, p. 23).

Esto es el reflejo de lo que por la pedagogía o la ley se ha materializado en el pueblo pues "las leyes de la educación son las primeras que recibimos. Y como nos preparan para ser ciudadanos, cada familia particular debe gobernarse conforme al plan de la gran familia que las comprende a todas" (Montesquieu, 1906 , p. 50). Así, si esta gran familia que es el Estado no está fundamentada en buenos principios fundantes de dinámicas justas y equitativas en pro de la dignidad del ser humano, por ende, los individuos producidos bajo estas lógicas van a estar acordes con la farsa de la gran familia porque "la corrupción de cada gobierno empieza casi siempre por la de su principio" (Montesquieu, 1906, p. 167).

Pero como no se educa para examinar y develar los principios rectores, sino que se enseña a trabajar a partir de un axioma dado como indiscutible, así aparezca como imperfecto simplemente está dado y no tiene sentido alguno entrar a considerarlo para reestructurarlo y menos para cambiarlo. Ya lo decía Montesquieu:

"El hombre, ese ser flexible que se amolda en sociedad a los pensamientos e impresiones de los demás, es tan capaz de conocer su propia naturaleza, si se le pone a la vista, como de perder hasta el sentimiento de ella si se le disfraza". (1906, p. 7) 


\section{El derecho como dominación en la contemporaneidad}

Es evidente que, para la contemporaneidad, la gran mayoría se encuentra perdida por el disfraz de la dominación que se presenta bajo un ideal muy diferente al que se pretende y mientras no se realice una deconstrucción de los principios primeros que constituyen las dinámicas socio jurídicas no se tiene cuándo establecer un orden sin corrupción porque:

"Una vez corrompidos los principios del gobierno, las mejores leyes se tornan malas y se vuelven contra el Estado. Si los principios se conservan sanos, las malas leyes producen el mismo efecto que las buenas: la fuerza del principio lo subyuga todo". (Montesquieu, 1906, p. 177)

Lo que se ha venido esbozando de manera somera y teniendo en cuenta la cita anterior no ha sido desconocido por los pensadores ilustres quienes legitimaron o denunciaron este fenómeno, pero tampoco ha sido desconocido por los comunes, quienes han vivido la tergiversación de los principios del derecho donde el efecto es contrario a lo que se pretende porque se favorece de manera constante a quienes por justicia y equidad no se les debería privilegiar; esto lo corrobora Bobbio (2003) cuando reconoce que "en una sociedad fuertemente dividida en clases contrapuestas, es probable que el interés de la clase dominante sea asumido y sostenido incluso por medio de la cohesión como interés colectivo" ( $p .242$ ).

Sin embargo, no se ha considerado de gran relevancia porque son casos que solo tocan a los que no tienen el recurso para hacer tambalear el orden jurídico establecido y si resultase quien lo hiciera, solo se modificarían algunos artículos que no obedecen a la estructura de dominación esencial; es decir, siempre se proponen soluciones a problemáticas que desestabilicen el orden social y que pongan en peligro el mantenimiento del poder y los intereses elitistas, pero dichas soluciones son solo formales, no esenciales, no van a los principios que deberían considerar, sino que se desvía la atención con una modificación, creación o inexequibilidad de una norma, lo que sirve como alivio para la masa, que más que justicia tiene sed de venganza. Esto uno de los problemas álgidos del derecho por la falta de reconstruir los principios o bases que originaron la violación de tal o cual derecho materializado en una acción entre particulares o con el Estado. 
Nietzsche, uno de los pensadores más críticos de todos los tiempos, lo expresaba tácitamente cuando mencionaba que "todas nuestras teorías políticas y todas las constituciones de nuestros Estados, incluyendo al Reich alemán por supuesto, son consecuencias, necesidades derivadas de la decadencia" (2005, p.51). Y si bien es cierto la decadencia en Nietzsche está referida a los principios de una moral débil debido a sus valores con tendencia a repudiar el cuerpo y sus deseos, también lo es que esta crítica al sistema político denominado decadente surge de la lectura de la historia donde se ha favorecido la muerte, persecución, e indignidad del ser antropológico en nombre de principios ideológicos y religiosos que se muestran como una contradicción en sí misma porque pretenden dignificar al hombre a través de su detrimento. Esto se evidencia con el proyecto de modernidad donde el imperativo era el desarrollo de los pueblos, pero:

"Es evidente, para tirios y troyanos, que lo que en verdad se han ido desarrollando, enriqueciendo y acumulando poder han sido los que en este desigual juego se habían situado desde antes como los más privilegiados en la estructura económica, social y política existente". (Escobar, 1998, p. 9)

Y, como ya se ha visto, el derecho ha sido cómplice en la medida que se entienda el derecho como un:

"Conjunto de las normas, u orden normativo, en el que se desenvuelve la vida de un grupo organizado, la política tiene que ver con el derecho desde dos puntos de vista: en cuanto la acción política se lleva a efecto a través del derecho y en cuanto el derecho delimita y disciplina la acción política". (Bobbio, 2003, p. 246)

En este contexto, mientras en un determinado lugar no se tengan las necesidades básicas cubiertas no se tendrán garantías para que la clase política deje de manipular la opinión pública y aprovechen las necesidades de los ciudadanos para beneficio personal. Este factor económico también incide de manera directa en las mentes más brillantes porque así tengan la concepción clara del dominio de la clase privilegiada se pone su potencial en servicio de la misma clase que ha detentado el poder para de este modo justificar sus políticas, que en última instancia afectan siempre a los más desfavorecidos de la sociedad. Se vislumbra entonces el hecho de que los mejores profesionales del derecho y 
de las ciencias políticas están al servicio de la élite coadyuvando a la legitimación de una ideología que deforma la realidad pues "no se niega que en la época contemporánea no haya reaparecido el monopolio del poder ideológico por parte del poder político" (Bobbio, 2003, p. 246). El cual, se inserta en las lógicas sociales para que el pueblo termine defendiendo posturas momentáneas que en realidad solo obedecen a intereses particulares, porque:

"El poder ideológico se basa en la posesión de ciertas formas de saber inaccesibles para la mayoría, de doctrinas, conocimientos, incluso solo de información o de códigos de conducta, para ejercer una influencia en la conducta ajena e inducir el comportamiento de un grupo para actuar de una forma en lugar de otra". (Bobbio, 2003, p. 242)

Y, por supuesto, la manipulación desde cualquier punto de vista no es conveniente para la dignidad del ser humano porque como se ha visto se deforma una realidad que es la base del pensamiento social y al estar tergiversada se tendrán razonamientos y juicios comunes sobre bases falsas lo que haría de facto el pensamiento posiblemente deformado. Cuando las bases de una sociedad se encuentran manipuladas hacia una distorsión de la realidad, el acto de pensar no garantiza una acción de libertad, sino que por el contrario es una reproducción de la voluntad dominante:

"Medítese bien en esto y se verá la causa de la corrupción de nuestra joven democracia. El número de semi-intelectuales es exagerado; luchan para adquirir el pan cotidiano por medio de representaciones en las asambleas del pueblo; allí, para conservar el favor, simulan fanatismos rabiosos; se establece un engranaje de pasiones repugnante: por eso la verdad tan vieja y que en fuerza de repetirse se ha vuelto banal, de que cada pueblo tiene el gobierno que merece, es irrefutable; la democracia es una forma buena o mala, según los tiempos y lugares". (González, 1919, p. 5)

De este modo la esperanza no está en la formación profesional o incluso tampoco en nuestros intelectuales porque son estos mismos, con excepciones obviamente, quienes desde la Antigüedad se han encargado de legitimar el orden político que ha sido excluyente y opresor; más si se tiene en cuenta la problemática contextual de Colombia donde el sostenimiento 
básico depende de la manipulación y del tráfico de influencias y donde si se tiene conocidos políticos o empresarios se obtiene un puesto con gran facilidad; de lo contrario el desempleo será el destino hasta que sea sometido a pensar y actuar acorde con unas premisas prestablecidas que son las del orden que absorbe los ideales más grandes hasta reducirlos al servicio de una empresa privada o del Estado. Así pues

"Lo que caracteriza más nítidamentela condición sociocultural de este fin de siglo es la absorción del pilar de emancipación por el de la regulación, fruto de la gestión reconstructiva de, los déficits y de los excesos de la modernidad confiada, en primer lugar, a la ciencia moderna, y en segundo lugar, al derecho moderno". (De Sousa, 2000, p. 59)

Se dilucida entonces un principio que se aplica constantemente por el derecho, que es la regulación, la cual absorbe por completo la emancipación; es decir, la libertad es solo una utopía porque al estar regulados constantemente y no darse la emancipación sino que por el contrario cada vez la ideología subordina y hace dependiente a una comunidad, bajo una estrategia que se ha vuelto común y que incluso la masa la reclama cuando no se le impone; esta estrategia es la disciplina, la cual se ha traído directamente del aparato militar donde el súbdito, el soldado, que en este caso es el pueblo, no puede pensar ni opinar, solo obedecer. El aparato jurídico con esta estrategia para la dominación ha sido un éxito: "El éxito del poder disciplinario se debe sin duda al uso de instrumentos simples: la inspección jerárquica, la sanción normalizadora y su combinación en un procedimiento que le es específico: el examen" (Foucault, 2002, p. 175).

La inspección jerárquica está relacionada con la mirada pública, que se convierte en presión, debido a la observación constante; en cuanto a la sanción normalizadora trata de que la pena que se pone no sea observada y se minimice el impacto causado. El examen es el poder ideológico de revisión de la conducta y avaluación de la misma, la cual se espera que esté acorde con los resultados que se proyectaron sin que la gran mayoría se percate de ello. Ya "Bentham ha sentado el principio de que el poder debía ser visible e inverificable" (Foucault, 2002, p. 205). Esto encaja perfecto en lo que se viene disertando porque la maquinaria del poder está camuflada de modo que 
solo sean tangibles los efectos, pero quien está detrás gusta de esconderse; tanto así que se dilata el poder de modo que se conforma el derecho como un aparato de dominación donde cada individuo que pone en marcha el aparato jurídico está funcionando en pro de quien detenta el poder y por ende la dominación. En palabras de Foucault:

"Hay una maquinaria que garantiza la asimetría, el desequilibrio, la diferencia. Poco importa, por consiguiente, quién ejerce el poder. Un individuo cualquiera, tomado casi al azar, puede hacer funcionar la máquina: a falta del director, su familia, los que lo rodean, sus amigos, sus visitantes, sus servidores incluso". (2002, p. 205)

Esto lo denominó Foucault como el panóptico que "es una máquina maravillosa que, a partir de los deseos más diferentes, fabrica efectos homogéneos de poder" (2002, p. 206). "Esa nueva legislación introduce procedimientos de dominación característicos de un tipo particular de poder. Una justicia que se dice "igual", un aparato judicial que se pretende "autónomo", pero que padece las asimetrías de las sujeciones disciplinarias" (Foucault, 2002, p. 233).

\section{Conclusiones}

Así, "la crítica ético-política tiene pretensión de establecer la no-verdad, la no-validez (deslegitimación), la no-eficacia de la decisión, norma, ley, acción, institución u orden político vigente e injusto desde la perspectiva específica de la víctima" (Dussel, 2001, p. 58). Se pretende entonces que se tomen cartas en el asunto, donde en un primer momento, como se ha mencionado en repetidas ocasiones, se realice el develamiento de los principios primeros que constituyen las dinámicas legales actuales para que de este modo se deslegitime la praxis socio jurídica que no esté acorde con las necesidades de las víctimas, es decir, de la clase que siempre ha estado excluida y oprimida y que nunca es tenida en cuenta realmente para las decisiones del Estado. Esto requiere una participación activa y una concepción crítica de la realidad de la que se desliguen inmediatismos políticos e intereses egoístas y se constituya el logos en un dialogo intersubjetivo que debe estar precedido por una reflexión de un pensar serio y autónomo pues: 
"No hay diálogo verdadero si no existe en sus sujetos un pensar verdadero, pensar crítico que, no aceptando la dicotomía mundo-hombres, reconoce entre ellos una inquebrantable solidaridad. Este es un pensar que percibe la realidad como un proceso, que la capta en constante devenir y no como algo estático". (Freire, 1969, p.75)

Se debe entonces garantizar que se tengan en cuenta las características propias de una comunidad y respetar las diferencias propendiendo siempre por que el marginado, el oprimido hable con voz propia porque nadie conoce mejor sus necesidades que él mismo. Esto aplica también para el país entero, donde se han adoptado sistemas legales de otros contextos que nada tienen de similar en cuanto a cultura y costumbres, teniendo en cuenta que la costumbre se considera como una fuente del derecho y si el derecho que se tiene en determinado lugar no está acorde con las costumbres de esa comunidad, por ende, no va a estar ajustado a las necesidades contextuales. Por ello,

"Desde el contexto histórico de América Latina creemos que el primer presupuesto es el de crear las condiciones para que los pueblos hablen con voz propia, es decir, para que digan su propia palabra y articulen sus logos sin presiones ni deformaciones impuestas". (Fornet-Betancourt, p. 8)

Cada comunidad comprende su propio logos; es por ello que sin caer en subjetivismos absolutos se debe tener en cuenta la posibilidad de cada individuo que conforma la comunidad porque al mismo tiempo las posibilidades de ese individuo están en cierto modo supeditadas por la comunidad micro y macro a la que este pertenece y el individuo en suma compone las dinámicas de las comunidades que las conlleva al desarrollo o al fracaso; es por ello que el derecho debe comprender el logos concreto del contexto al que se está aplicando para que el individuo se identifique con el derecho que le es brindado y se apropie del mismo expandiéndolo a los demás. Así se evita que se torne el derecho en una imposición de una ideología determinada que además es ajena y pugna con las características socioculturales de los individuos que la componen; de este modo, "la idea es facilitar que cada persona tenga los recursos y la oportunidad para cultivar virtudes y relaciones valiosas, y disfrute las buenas cosas en vida" (Chan, 2001, p. 28). El derecho surge precisamente de los conflictos entre partes; por ello son esenciales las buenas relaciones conformadas desde unos principios meramente 
humanos para que el aparato jurídico no esté a favor de una sola clase, sino que sea el verdadero derecho que no discrimine por quien tenga poder o mayor capital sino por quien invoque la protección de su derecho y se haga una justicia real, como se proponía en la cultura oriental que:

"Aunque ellos sean descendientes de reyes y duques, o caballeros e ilustres funcionarios, si son incapaces de observar devotamente los requerimientos del ritual y los principios morales, deberían ser relegados a la posición de los inferiores. Aunque ellos sean los descendientes de los inferiores, si acumulan cultura y estudio, rectifican su carácter y conducta, y son capaces de observar devotamente los requerimientos de los principios rituales y la justicia, deberían ser llevados a los rangos de un primer ministro, caballero o ilustre funcionario". (Chan, 2001, p. 12)

Este es un gran ideal de derecho donde está inmersa la justicia, de modo que quien observe las conductas acordes con la cosmovisión de una época en un lugar determinado tenga la posibilidad de la recompensa y quien por el contrario las deje de lado sin importar su posición socioeconómica obtenga lo adverso de los que actúan observando este derecho, propendiendo no por una sed de castigo sino porque se modifiquen las conductas para el bien de la sociedad. 


\section{Referencias}

Al-Farabi, A. (1995). La ciudad ideal. Madrid: Editorial Tecnos.

Al-Kindī. (1974). Para al-Mu'tasim Billāh. Sobre la filosofía primera, capítulo IV, parte 1. Althusser, L. (2003). Ideología y aparatos ideológicos del Estado.

Alvarado, L. y García, M. (2008). Características más relevantes del paradigma sociocrítico: su aplicación en investigaciones de educación ambiental y de enseñanza de las ciencias realizadas en el Doctorado de Educación del Instituto Pedagógico de Caracas. Revista Sapiens. 9 (2), pp. 187-202. Recuperado de: https://www.redalyc.org/articulo.oa?id=41011837011

Aristóteles. (1985). Ética nicomáquea. Ética Eudemia. Madrid: Editorial Gredos. Disponible en: https://docs.google.com/a/unad.edu.co/file/d/OB4WPmIZmhwZeXFGSmhwYzFZbkU/edit?pli=1

Aristóteles. (1988). Política. Madrid: Gredos. Disponible en https://docs.google.com/a/unad.edu.co/file/d/OB4WPmIZmh-wZczFaX3FFZXhIR1E/edit Avicena. (1950). Sobre metafísica. Madrid: Revista de Occidente.

Bobbio, N. (2003). Teoría general de la política. Madrid: Editorial Trotta.

Chan, J. (2001). Producción del sentido de justicia confuciana. Recuperado de https:// them.polylog.org/3/fcj-es.htm

Cicerón, M. T. (s.f.). De la Republica. Tomo VI.

De Aquino, T. (2001), Suma de Teología. Madrid: Biblioteca de autores cristianos.

De Hipona, A. (s.f.). La Ciudad de Dios.

De Sousa, B. (2000). Crítica de la razón indolente. Contra el desprecio de la experiencia. Volumen uno. Editorial Desclée, de Brouwer. S.A. Recuperado de http:// www.boaventuradesousasantos.pt/media/critica_de_la_razon_indolente.pdf

Dussel, E. (2001). Hacia una filosofía política crítica. Bilbao: Descleé De Brower. Recuperado de http://enriquedussel.com/txt/53. Hacia_filosofia.pdf

Fornet-Betancourt, R. (s.f.). Filosofía intercultural. Universidad Autónoma de Nayarit. Recuperado de http://www.olimon.org/uan/intercultural.pdf

Foucault, M. (2002). Vigilar y castigar, nacimiento de la prisión. Siglo Veintiuno editores Argentina S.A.

Freire, P. (1969). Pedagogía del oprimido (edición incompleta). Santiago.

Galbraith, J. K., y Aleu, J. F. (1984). La anatomía del poder. Plaza \& Janés.

González, F. (1919). Una Tesis - El derecho a no obedecer. Medellín: Universidad Pontificia Bolivariana, marzo de 1995.

Hobbes T. (s.f.). Leviatán. Biblioteca del Político. Recuperado de http://juango.es/files/ hobbes-leviat-n.pdf

Maquiavelo, N. (1998). El Príncipe. Madrid: Espasa Calpe S.A.

Martínez, R. (2011). La hermenéutica y las bases epistemológicas de la investigación educativa. Décimo Primer Congreso Nacional de Investigación Educativa. México: Universidad Autónoma Nuevo León. Recuperado de http://www.comie.org.mx/congreso/memoriaelectronica/v11/docs/area_11/0910.pdf

Montesquieu. (1906). El Espíritu de las Leyes. Madrid: Librería General de Victoriano Suarez.

Nietzsche, F. (2005). El ocaso de los ídolos. Recuperado de_http://juango.es/files/ElOcaso-de-los-Idolos.pdf 